\title{
Biblioteca Virtual de Letras
}

\author{
Leandra Fagundes da Silva* \\ Luthiano Rodrigues Venecian ** \\ Elton Luiz Vergara Nunes ${ }^{* * *}$
}

Resumo: O presente artigo pretende mostrar o estado atual da Biblioteca Virtual de Letras, projeto de pesquisa do Curso de Letras da UFPel, que visa a disponibilizar, através de um site na web, obras da área, especialmente da literatura universal, de forma gratuita e rápida, integrando tecnologia $e$ educação, Ao mesmo tempo em que serve de campo de aprendizagem para os participantes do projeto, presta excelente serviço aos seus usuários. Através da análise dos dados obtidos pelas estatísticas do site, enquetes on-line, bem como pela apreciação das mensagens recebidas por e-mail, pode-se avaliar a importância de tal iniciativa, o que tem levado a equipe à ampliação e refinamento dos serviços oferecidos. Pretende-se aqui, ainda, apresentar a forma como se constituiu o site e as perspectivas de ampliação.

Palavras-chave: BIBLIOTECA, VIRTUAL, LETRAS, LITERATURA, TECNOLOGIA

Virtual Library of Letters

Abstract: The present article wants to show the actual state of the Virtual Library of Letters. This project of research belongs to the Course of Letters of the UFPel, whose principal aim is to lay before, through a site of web, workmanships of the area, especially about universal literature, without payment and in a fast form, integrating technology and education. At the same time it serves of field of learning for the participants of the project, it gives excellent service to its users. Through the analysis of the data gotten for the statisticians of the site, researches on-line, as well as for the appreciation of the messages received for $e$-mail, we can be evaluate the importance of such initiative, that it has taken the team increase and improve the offered services. Here, we also intend to present the form how is the site constituted and the perspectives of amplification.

Keywords: LIBRARY, VIRTUAL, LETTERS, LITERATURE, TECHNOLOGY

\section{Introdução}

\section{A importância de uma Biblioteca Virtual de Letras}

Com o objetivo de "disponibilizar obras digitalizadas da área de Letras, encontráveis na Internet, para os usuários do site, de maneira organizada, gratuita e rápida" foi criado um projeto de pesquisa que visa a propiciar um primeiro contato com obras literárias e artigos científicos, servindo de motivação à aquisição e acesso às obras impressas. Para atingir esses propósitos, foi criado um site na web que conta com um banco de dados, alimentado on-line pela equipe de alunos e professores participantes do Projeto, a partir de arquivos encontrados, selecionados e classificados pelos pesquisadores.

A Biblioteca Virtual de Letras atende a uma necessidade de estudantes e professores ao facilitar o acesso a obras literárias de diferentes gêneros, assuntos e em diferentes idiomas. Visa a motivar a leitura e o contato com obras que muitas vezes são de difícil acesso seja por sua raridade, seja por seu alto custo. Além da disponibilização das obras literárias, é um espaço para a produção dos alunos e professores da área de

\footnotetext{
* Licenciada em Língua Espanhola, Pós-graduanda em Leitura e Produção Textual, UFPel, likmichelena@terra.com.br

*** Estudante de Ciências da Computação da UCPel, bolsista da UFPel, luthiano@ufpel.edu.br

${ }^{* * * *}$ Professor de Espanhol da UFPel, Mestre em Educação, coordenador da Biblioteca Virtual de Letras http://www.ufpel.edu.br/bvl/, vergaranunes@bol.com.br
} 
Letras, com trabalhos acadêmicos e de participações em congressos, seminários, cursos e palestras. Também se disponibilizam na Biblioteca biografias de autores, elaboradas pelos alunos do Projeto. A Biblioteca Virtual é também um espaço aberto à colaboração de autores novos que queiram disponibilizar seus trabalhos.

Devido aos seus propósitos e configuração, está classificada na linha de pesquisa da "Tecnologia Educacional", tendo como subárea de conhecimento, Letras. O Projeto começou suas atividades em 01 de novembro de 2002, com um trabalho com alunos de catalogação de algumas obras, que serviu de base para a elaboração de um modelo de cadastro para as obras do futuro acervo, que fosse simplificado e de fácil compreensão ao usuário.

A Biblioteca Virtual de Letras está, como qualquer biblioteca, a serviço da difusão cultural através de livros. Não digitaliza nenhuma das obras que disponibiliza, apenas as coloca em suas estantes virtuais. As obras disponíveis são adquiridas em sites diversos na Internet, sempre gratuitos, ou seja, disponíveis a qualquer internauta.

A Biblioteca Virtual de Letras foi apresentada como Projeto de Pesquisa ao Departamento de Letras da Universidade Federal de Pelotas como uma possibilidade de estudo, visando à integração da internet e o ensino de letras.

1. Tendo como objetivo "disponibilizar livros eletrônicos, encontráveis na Internet de maneira organizada, gratuita e rápida", a BVL tem procurado atender às expectativas a que se propôs desde sua criação.

\section{Como tudo começou}

O atual coordenador do Projeto BVL possuía, em seu computador, vários arquivos de obras de literatura de língua espanhola, encontrados na Internet. Como contava com um volume grande de obras, surgiu a idéia de oferecê-las a outras pessoas. Inicialmente, as disponibilizou na área de espanhol, dentro de um site que mantinha para o curso de Letras da UFPel. Logo, foram acrescentadas obras em outras línguas.

O número de arquivos cresceu muito, bem como as demais áreas do site, que havia se tornado grande demais, com diferentes serviços. Surgiu a idéia então de se criar um portal, que passou a chamar-se Ciberletras, dedicado especialmente à área de letras, hospedando diversos sites específicos; dentre estes, a BVL.

Em janeiro de 2003, foi inaugurado o portal contendo o site da BVL. O mesmo recebeu a estrutura e o designer que serviram como referência para as futuras modificações. A partir daquele momento, passou a contar com um banco de dados Access, em plataforma Windows, com páginas em asp, em servidor pago. Este foi o primeiro grande passo desde que a BVL passou a ser um Projeto de Pesquisa aprovado pela UFPel, quando também se converteu em Grupo de Pesquisa registrado no CNPq. Passaram a integrar o grupo diversos professores e alunos; a equipe passou a contar também com o serviço de um programador da área de informática e dois webdesigners.

Com o rápido crescimento da BVL e um considerável aumento em seu acervo virtual, tornou-se necessário um espaço maior no servidor. Em abril de 2003, a BVL passou a contar com um domínio próprio (bvletras.com) e um espaço de $600 \mathrm{Mb}$, em um servidor Windows pago. Todo o conteúdo que estava no ciberletras.com foi transferido para o novo espaço. 
Por outro lado, em junho de 2003, por uma série de motivos pessoais e profissionais do coordenador, o portal Ciberletras saiu do ar, desaparecendo cerca de 35 sites. O conteúdo de alguns desses sites foram organizados em forma de textos e convertidos em arquivos que passaram a integrar o acervo da BVL, entre eles: Histórias em Quadrinhos na Educação, Pedagogia da Internet, Refranero Español, artigos de Lingüística Aplicada. O ciberletras.com passou, desde então, a ser redirecionado para bvletras.com.

A partir de setembro de 2003, começou a ser cogitada a possibilidade de a BVL ser hospedada no servidor da UFPel. Dois importantes motivos levaram a isso: 1) por ser grátis, já que, até então, os custos do projeto estavam sendo custeados pessoalmente pelo coordenador e, 2) porque o servidor da UFPel tinha recebido investimentos, ampliando sua velocidade de transmissão de dados e capacidade dos equipamentos, o que melhorou em muito sua qualidade, possibilitando o atendimento das expectativas do Projeto.

2. A partir de 24 de novembro de 2003, começou o processo de migração para o servidor da Universidade Federal de Pelotas, numa plataforma Linux, com um banco de dados Mysql e páginas php. Esse processo foi concluído em 24 de janeiro de 2004, quando se reinauguraram as atividades da BVL e o site foi aberto ao público.

\section{A Biblioteca em números}

Em abril de 2003, quando se constituiu em domínio próprio e recebeu um espaço exclusivo no servidor Windows, a BVL passou a contar com um serviço de estatísticas que permitiu identificar com precisão o tipo de usuário, do ponto de vista de origem e equipamento usado. Nesse período, até 24 de janeiro deste ano, a média de visitas diárias foi de cerca de 20 usuários únicos. A partir desta data, quando se reinaugurou no servidor Linux da UFPel, a média cresceu para 23 acessos diários com projeção ascendente.

O site foi planejado para uma resolução de 800x600, o que se revelou importante, visto que cerca de $67 \%$ dos usuários usa esta resolução, sendo seguido por $30 \%$ de usuários que usam resolução de $1024 \times 768$; isto foi previsto em seu design, não havendo problema em nenhum dos casos.

No que se refere a navegador, o Internet Explorer 6 é o mais usado com cerca de $51 \%$ dos usuários, seguido pelo Internet Explorer, versão 5x, com $47 \%$ dos usuários. No planejamento dos recursos e do design da BVL, esta tendência de uso foi considerada.

O sistema operacional mais usado ainda é o Windows, sendo a versão 98 a de maior peso, com 53\%, seguida pelo XP com 36\%. Menos de meio por cento dos usuários da BVL usam o Linux como sistema operacional. O uso do XP facilita na questão dos arquivos compactados com extensão zip, dispensando a instalação de software descompactador para os arquivos do acervo.

Até o momento, a BVL utilizou como recurso de divulgação apenas o envio de um convite por e-mail aos usuários que haviam se cadastrado no portal ciberletras.com, conta com um link no portal da UFPel e com redirecionador do ciberletras.com para o endereço atual da BVL.

Em relação aos países de origem dos visitantes, o Brasil, evidentemente, é o país com o maior número de acessos. No domínio bvletras.com, os Estados Unidos ocupavam a segunda posição em visitas, o que pode dever-se ao fato de ser um domínio 
pontocom. Durante esse período, foram recebidos visitantes de diversos países, entre eles Alemanha, Arábia Saudita, Argentina, Brasil, Canadá, Chile, Colômbia, Espanha, Estados Unidos, França, Guatemala, Hong-Kong, Hungria, Ilhas Seichelles, Israel, Itália, Japão, México, Noruega, Países Baixos, Panamá, Peru, Portugal, Reino Unido, Suíça e Uruguai. Este tipo de dado não está mais sendo monitorado.

Os serviços de estatísticas atualmente usados são grátis (Site Meter em http://www.sitemeter.com e Bravenet em http://www.bravenet.com), portanto, bastante limitados e não pertencem ao servidor da UFPel; entretanto, o técnico responsável pela programação informática está, neste momento, trabalhando para a elaboração de um pacote para o controle completo das estatísticas. O propósito é monitorar constantemente a tendência do perfil do usuário com mais precisão, a fim de oferecer melhores serviços.

3. Em termos de quantidades, o acervo da BVL conta com mais de 1500 arquivos. Desde sua re-inauguração, foram inseridos mais de 400 novos arquivos. Há ainda cerca de 3500 arquivos a serem identificados, organizados, selecionados, classificados e inseridos no acervo da Biblioteca, evidenciando um grande trabalho ainda a ser realizado. Todos os arquivos do acervo estão em formato zip, para que ocupem menos espaço no servidor. Os arquivos compactados são de diferentes tipos, sendo a maioria em formato doc (ou rtf) do Word e pdf (da Acrobat), entretanto, alguns arquivos podem encontrar-se em formato txt (Bloco de Notas) ou html. Optamos por esses formatos por tratar-se de extensões conhecidas em geral não precisando de instalação de nenhum novo software além daqueles que as pessoas costumam ter em seu computador pessoal.

Finalmente, o controle do número de arquivos copiados do acervo da BVL aponta para um motivador resultado. Até o momento já se aproximam de sete mil arquivos copiados, aumentando diariamente. Em ordem decrescente, as dez obras mais copiadas são:

\begin{tabular}{clc} 
Posição & \multicolumn{1}{c}{ Título da Obra } \\
Divina Commedia - Inferno & Cópias \\
$1^{\circ}$ & 452 \\
$2^{\circ}$ & Édipo Rei & 434 \\
$3^{\circ}$ & A Terceira Margem do Rio & 318 \\
$4^{\circ}$ & A Causa Secreta & 307 \\
$5^{\circ}$ & Divina Commedia - Paradiso & 249 \\
$6^{\circ}$ & O Alienista & 247 \\
$7^{\circ}$ & Dom Casmurro & 235 \\
$8^{\circ}$ & A Rua Diferente & 182 \\
$9^{\circ}$ & O Crime do Padre Amaro & 168 \\
$10^{\circ}$ & Iceberg & 104
\end{tabular}

\section{Perfil do usuário da BVL}

Com base nos dados encontrados nos e-mail's, pode-se constatar que a grande maioria dos usuários da BVL é composta por pessoas que utilizam a internet esporadicamente, muitas vezes apresentando necessidades imediatas e específicas, reveladas através de dúvidas que podem parecer a usuários avançados como dominadas. Movimentar-se dentro do site, usar as buscas internas ou mesmo copiar um arquivo através de um link determinado podem ser dificuldades suficientes para que um usuário inexperiente desista de usar os serviços oferecidos. Pensando em atender melhor a esses 
usuários, os integrantes do Projeto estudaram diferentes alternativas para facilitar o acesso ao acervo e a todo o conteúdo disponível, bem como melhorar a usabilidade do site. Para tanto, a equipe de professores, juntamente com o técnico em informática, discutiram alternativas para o ambiente que propiciassem essas facilidades, que serão descritas abaixo.

O usuário da BVL é estudante universitário. Mais de 52\% dos cadastrados são estudantes de nível superior, especialmente da área de Letras e outras das ciências humanas. Esses dados do cadastro são corroborados pelas mensagens recebidas através da página de "contato" do site, em que manifestam sua relação com as letras. Essas mensagens recebidas por e-mail também confirmam uma outra parcela de usuários, com $21 \%$ do total, que são estudantes do ensino médio. Esse estudante é marcadamente um potencial candidato à universidade, já que acessa o site da BVL em busca de obras para os exames vestibulares.

Através das mensagens recebidas é possível perceber uma relação positiva de satisfação dos usuários com relação aos serviços oferecidos, entretanto, devido à inexperiência de navegação de muitos, ainda indicam dificuldades encontradas nesse acesso. Esse perfil de usuário se encaixa nos propósitos da Biblioteca, que é o de facilitar o acesso a obras da área de letras. A definição desse perfil foi usada como referência para a criação de um serviço específico que vai atender grande parte dos visitantes: as obras de vestibular.

\section{Serviços}

O site da Biblioteca Virtual de Letras dispõe de diferentes serviços para seus usuários, que levam em conta o perfil definido através das enquetes, estatísticas, cadastros e mensagens de e-mail. Esses serviços visam a facilitar a navegação.

Na página inicial, o visitante já pode copiar - com apenas um clique no mouse as dez obras mais procuradas do acervo ou as cinco últimas inclusões. Caso não queira nenhuma dessas, pode procurar a obra desejada inserindo o nome ou parte do nome da obra num campo de busca na página inicial, ou, se preferir, pode clicar em "busca avançada" e detalhar sua busca com o nome do autor, gênero, idioma, título da obra ou ainda com o cruzamento de quaisquer desses dados, refinando sua busca. É importante frisar a possibilidade de uso da busca simples, ou do link para a busca avançada, em qualquer uma das páginas do site, sem necessidade de voltar a home para isso.

Na página com o resultado da busca são listadas todas as obras disponíveis que se encaixam no padrão utilizado e já podem ser copiadas com um clique sobre o ícone da obra. Se preferir, pode clicar sobre o nome da obra e ver toda as informações disponíveis. Cada obra possui uma ficha de cadastro com os seguintes dados: título disponível, título em português, nome completo do autor, gênero em que a obra está classificada, idioma disponível da obra no acervo, tamanho do arquivo e uma pequena apresentação, que possibilita ao usuário conhecer dados básicos antes de decidir copiá-la ou não. Nessa ficha, estão disponíveis ícones que permitem ao usuário acessar, com apenas um clique, a biografia do autor (onde encontrará seu nome completo, fotografia e dados de sua vida e produção), a lista de obras do referido autor disponíveis no acervo, a lista de outras obras do mesmo gênero, e a uma lista contendo todos os títulos do acervo disponíveis no mesmo idioma. Nas listas abertas, o usuário pode imediatamente copiar qualquer um dos títulos com apenas um clique sobre o ícone que sempre acompanha as obras, ou clicar sobre o título e ver sua ficha. 
Abaixo da caixa de busca simples que aparece em todas as telas do site, o visitante dispõe de um menu onde pode saber mais sobre o Projeto BVL, tal como conhecer a equipe técnica, dados sobre o projeto, créditos, cadastrar-se e também entrar em contato com os administradores. É importante frisar que a busca simples, os ícones do menu, o link para a busca avançada, bem como as dez obras mais copiadas e as últimas cinco inclusões estarão sempre disponíveis para o usuário não importando em que página do site se encontre. Além disso, o usuário da BVL sempre poderá voltar à página inicial, bastando clicar no logo do site no canto superior esquerdo, seguindo um padrão da web.

Na página inicial, o visitante poderá ainda dar sua opinião numa enquete que traz perguntas significativas para o meio acadêmico e também pode acompanhar os resultados com apenas um clique. Com base num controle de IPs, o sistema permite que se vote apenas uma vez. Ainda nesta página, o usuário dispõe de notícias que podem ser lidas de forma integral ou apenas seu resumo.

Caso tenha interesse em receber informações por e-mail, o visitante pode cadastrar-se clicando no ícone do menu, bem como enviar recados através de um formulário de contato.

Outro serviço presente na home é o "Autor do Mês". Ao clicar na foto desse autor, é possível visualizar sua biografia bem como ter acesso direto a todas obras do referido autor disponíveis no acervo.

4. Como resposta ao perfil identificado de usuário bem como aos propósitos do Projeto, através de um link visível em todas as telas, pode-se obter obras de vestibulares de universidades brasileiras. Ao clicar nesse link, abre-se uma lista contendo os nomes das instituições cadastradas. Também é possível localizar a intuição desejada com o apoio de um motor de busca específico para esta área. Ao escolher a instituição, são listadas as obras disponíveis no acervo, exigidas para seu concurso vestibular. As obras podem ser copiadas com apenas um clique no ícone característico. Também nesta página é possível conhecer mais sobre as obras bastando clicar sobre o título, que abrirá a ficha de cadastro com todas as informações já citadas.

\section{Gerenciamento da Biblioteca Virtual de Letras}

Todo o gerenciamento da BVL é realizado através de uma área restrita de acesso exclusivo aos participantes do Projeto, cadastrados pelo coordenador. A área restrita é personalizada conforme o tipo de informação dada pelo coordenador no cadastro do membro da equipe. Existem três níveis de acesso à área restrita: alunos, professores e administrador. Para cada nível de acesso estão habilitados recursos específicos, conforme as tarefas a serem executadas pelo membro da equipe.

5. Nessa área é possível, de acordo com o nível de acesso:

1) Inserir autores: Inserção do nome completo do autor, cujas obras se disporá no acervo virtual. Nesta inserção também se inclui a foto do autor, que mantém um padrão de tamanho máximo de 235x177 pixels, em tons de verde. As fotos são editadas antes de serem enviadas. Caso não haja foto disponível para o referido autor, o sistema insere uma imagem padrão automaticamente. Nesta área é possível modificar esses dados ou excluir o autor. 
2) Inserir idiomas: Inserção, alteração ou exclusão de idiomas das obras que serão disponibilizadas no acervo.

3) Gênero das obras: Inclusão dos diferentes gêneros nos quais se classificam as obras da Biblioteca. Nesta área é possível modificar ou excluir itens.

4) Inserir obras: A inserção de obras é feita através do preenchimento de uma ficha catalográfica com o nome completo do título da obra que será disponibilizado, título da obra em sua publicação em língua portuguesa além do preenchimento dos demais dados com base nos campos acima citados, através de definição desses dados nas respectivas caixas de seleção. Para a inclusão do arquivo da obra, há um botão "procurar" que abre uma caixa de diálogo que permite localizar o arquivo no computador do responsável pela inclusão. O tamanho máximo do arquivo a ser enviado pela área restrita é de $4 \mathrm{Mb}$. Arquivos maiores poderão ser enviados apenas por ftp, sendo necessário o preenchimento dos dados na ficha catalográfica e alteração manual do tamanho do arquivo diretamente na base dados. É necessário enviar um (falso) arquivo - que será substituído no servidor por Ftp - a fim de terminar o processo de envio. Ao excluir um título na área restrita, o arquivo é deletado, evitando lixo no servidor.

5) Apresentar obras: Inclusão de um pequeno texto referente á obra, onde são inseridas informações mínimas que auxiliarão o usuário a decidir seu interesse ou não pela obra, antes de copiá-la para seu computador. A caixa de edição, onde é inserido o texto, aceita tags html. Os textos das apresentações são curtos, não passando de 100 palavras. As apresentações das obras são inseridas automaticamente na ficha catalográfica de cada título, bem como a informação sobre o tamanho do arquivo, calculado automaticamente pelo sistema, quando da inclusão da obra.

6) Definir autor do mês: Através da listagem completa dos autores cadastrados na BVL, o administrador pode selecionar um e defini-lo como "Autor do Mês". O "Autor do Mês" aparece na página inicial com um link que abre sua biografia e lista de obras disponíveis.

7) Inserir notícias: $\mathrm{O}$ administrador pode inserir, alterar ou excluir notícias, que ficarão disponíveis no mural da página inicial. A caixa de edição das notícias aceita tags html.

8) Administrar enquetes: $\mathrm{O}$ administrador pode inserir, alterar, excluir e definir enquetes nesta área. O número de votos inicial para cada opção também pode ser pré-definido. O número máximo de opções na enquete é oito, sendo possível a escolha de apenas uma opção pelo respondente. Há um controle de IPs que limita a participação do usuário a apenas uma vez por enquete. Os resultados da enquete são apresentados em forma de número de votos, porcentagem e gráfico.

9) Gerenciamento da equipe: $O$ administrador pode inserir, alterar, ou excluir logins de acesso à área restrita para os membros da equipe do Projeto. Cada membro da equipe pode alterar seus dados pessoais com exceção de seu login. Somente o administrador pode fazer exclusões.

10)Gerenciar cadastrados: Os usuários cadastrados da BVL podem atualizar seus dados ou excluir-se da base de dados através do link disponível 
na página de cadastro. $\mathrm{O}$ administrador pode executar as mesmas ações através da área restrita.

11)Incluir biografias: Para inserir uma biografia, o aluno membro da equipe deve escolher o nome do autor numa caixa de seleção onde estão todos os autores cadastrados da BVL, que ainda não têm biografia disponível. As biografias são elaboradas pelos alunos da respectiva equipe e enviadas através da área restrita, em um campo editável que aceita tags html. As biografias enviadas pelos alunos ficam em uma área temporária, aguardando a autorização do professor responsável por esta tarefa. Para fazer a autorização, o professor responsável deve selecionar o autor desejado, a partir de uma listagem de autores cujas biografias foram elaboradas pelos alunos e aguardam a aprovação. Na página de biografia do autor, aparecem para o visitante do site dois tipos de mensagens: 1) caso não exista biografia redigida, "Não disponível"; 2) caso a biografia tenha sido redigida pelo aluno, e apenas aguarda a liberação pelo professor responsável, "Em breve, esta biografia estará disponível”. Caso a biografia já esteja disponível, o visitante pode conhecer melhor o autor desejado. São inseridos automaticamente, como título, o nome completo do autor e sua foto.

12)Relatórios: $\mathrm{Na}$ área restrita, o administrador pode solicitar relatórios de inclusão de obras, biografias autorizadas e apresentações disponibilizadas, definindo o período desejado de abrangência do relatório. Esses relatórios servem de base para as notícias por e-mail.

13)Envio de mensagens: Semanalmente, o administrador envia notícias por e-mail aos usuários cadastrados. O conteúdo da mensagem é colocado em um formulário que envia essas informações através de um arquivo que tem como base os dados do banco com os endereços dos cadastrados.

14)Obras de vestibulares: Primeiramente, a equipe responsável insere os nomes das instituições em formulário próprio, informando o período de realização do vestibular a que se refere. No segundo momento, escolhe o nome da instituição, na caixa de seleção com os nomes de todas as instituições cadastradas, e se abre uma nova caixa de seleção, agora com todas as obras disponíveis no acervo. São selecionadas as obras indicadas pela instituição para o concurso vestibular registrado anteriormente. Através de um link na página inicial (que aparecerá em todas as telas), o usuário pode acessar esses dados.

\section{Equipes de trabalho}

Atualmente o Projeto conta com a participação de cinco professores e cinco alunos do curso de Letras, um técnico em informática e um webdesigner. Todos estão divididos em equipes, sendo cada uma coordenada por um professor. São elas:

- Inclusão de Obras

Prof. Elton Luiz Vergara Nunes e a aluna Leandra Fagundes da Silva

- $\quad$ Apresentação e Classificação das Obras

Prof. Aulus Mandagará Martins e as alunas Carolina Carrett Peres e Laís Lima da Costa

\section{- Textos Acadêmicos}


Prof. Paulo Ricardo da Silveira Borges

- Biografias dos Autores

Profa. Jaqueline Thies Krochier e a aluna Liliane da Silva Prestes

- Obras de Vestibulares

Profa. Denise Pérez Lacerda e a aluna Aline Medeiros Nunes

A partir de março de 2004, o Prof. Paulo Borges retorna de seu doutorado, assumindo a equipe de seleção e inclusão de textos acadêmicos e artigos de interesse para a área de Letras. Pretende-se que tal seleção seja feita por um "conselho editorial" a fim de dar confiabilidade às publicações ali veiculadas.

Também passam a compor a equipe as professoras Beatriz Helena da Rosa Pereira e Fabiane Tejada da Silveira, colaboradoras no novo projeto chamado Audioteca Virtual de Letras, cujo objetivo principal é "disponibilizar arquivos eletrônicos de obras ou parte de obras literárias, para os usuários da Internet de maneira organizada, gratuita e de fácil acesso, de arquivos de textos disponíveis na Biblioteca Virtual de Letras, através das páginas da BVL, na forma de gravações". Farão parte desse novo Projeto dois alunos de cada área do curso de Letras, bem como o grupo de teatro do Instituto de Letras e Artes.

\section{Conclusões}

Com base nos dados mencionados, pode-se constatar que a Biblioteca Virtual de Letras trata-se de um projeto arrojado e inovador que visa à democratização do acesso de obras para os usuários da internet que tenham interesse em adquiri-las de forma gratuita, através download, em um único site, com a finalidade de suprir as necessidades dos internautas.

Em termos de tecnologia, o sistema se adaptou tranqüilamente ao servidor da UFPel, tendo em vista a ampliação do acervo da BVL. Outro sucesso encontrado é o significativo acréscimo do número de acessos diários como resposta à divulgação do novo endereço e à proposta do Projeto da BVL. O sistema mostrou-se confiável e robusto, capaz que absorver essa demanda.

Embora, a BVL tenha, durante a migração, mudado de banco de dados Access para Mysql e também de asp para php, não houve perda do acervo, tampouco perda dos dados armazenados na base anterior.

Constatou-se também, a satisfação dos usuários da BVL no novo servidor, uma vez que não foi recebida nenhuma mensagem negativa relacionada à velocidade de acesso e de download das obras até o presente momento.

É importante salientar que, embora venha atendendo aos propósitos para os quais foi criada, a BVL está em constante aperfeiçoamento, buscando ampliar seus serviços e melhorar a qualidade do trabalho realizado. Para tanto, novos projetos estão sendo incluídos, como a Audioteca Virtual de Letras, e a equipe de pessoas envolvidas vem sendo ampliada. 


\section{Bibliografia}

1. CHAVES, Eduardo. Conceitos básicos: tecnologia na educação e ensino a distância. Disponível em: <http://www.edutecnet.com.br/Tecnologia e Educacao/edconc.htm Acesso em: 14 out. 2001.

2. FOLHA ONLINE. O perfil do internauta brasileiro. Disponível em: $<$ http://www.uol.com.br/folha/informatica/2001-ibrands-pesquisa.shtml Acesso em: 13 mar. 2002.

3. LEITE, Lígia Silva. O desenvolvimento da EAD. Disponível em: <http://www.intelecto.net/desenvolvimento_ead.htm> Acesso em: 17 nov. 2001.

4. MARQUES, Mário Osório. A escola no computador. Ijuí: Editora Unijuí, 1999.

5. MORAN, José Manuel. A internet na educação. Disponível em: <http://www.eca.usp.br/prof/moran/entrev.htm> Acesso em: 10 dez. 2001.

6. MORAN, José Manuel. Como utilizar internet na educação. Disponível em: <http://www.eca.usp.br/prof/moran/internet.htm> Acesso em: 16 dez. 1999.

7. MORAN, José Manuel. Ensino e aprendizagem inovadores com tecnologia. Educacional. Disponível em:

$<$ http://www.educacional.com.br/entrevistas/entrevista0025.asp > Acesso em: 12 out. 2001.

8. MORAN, José Manuel. Mudar a forma de ensinar e aprender com tecnologias. Disponível em: <http://www.eca.usp.br/prof/moran/uber.htm> Acesso em: 10 dez. 2001.

9. RIBEIRO, José Carlos S. Hipertextualidade e cultura contemporânea. Disponível em: <http://www.facom.ufba.br/hipertexto/cultura.htm> Acesso em: 14 out. 2001.

10. USABILIDADE. Algumas dicas sobre usabilidade: adaptação da obra Projetando Websites de Jakob Nielsen. Disponível em: <http://www.fcc.univap.br/ lubia/progint/usabilidade.html> Acesso em: 12 mar. 2002 .

11. VALENTE, José Armando. Por que o computador na educação. Governo do Brasil: MEC Disponível em: <http://www.proinfo.gov.br/biblioteca/textos/t> Acesso em: 09 ago. 2001.

12. VERGARA NUNES, Elton L. La pedagogía de internet: una perspectiva en la enseñanza a distancia de lenguas extranjeras. Tonos Digital, v. III, 2002. Disponível em <http://www.um.es/tonosdigital/znum3/pdfs/estudiospedagogiainternet.pdf> Acesso em 10 nov. 2003.

13. VERGARA NUNES, Elton L.; PIRES, María A.; CHARRUA, Carmen Lencastre de Albuquerque. Enseñanza de idiomas a través del uso de las nuevas tecnologias: métodos de español y portugués en internet y en CD-ROM. In: Educación: retos de la alfabetización tecnológica en un mundo en red. Mérida: Junta de Extremadura, Consejería de Educación, Ciencia y Tecnología, 2000. p. 8391. 